Review

\title{
The use of imaging techniques in understanding lower urinary tract (dys)function
}

\author{
Yves Deruyver a , Lukman Hakim ${ }^{\mathrm{a}, \mathrm{b}}$, Jan Franken a ${ }^{\mathrm{a}}$, Dirk De Ridder ${ }^{\mathrm{a}, *}$ \\ a Laboratory of Experimental Urology, Department of Development and Regeneration, KU Leuven, Leuven, Belgium \\ ${ }^{\mathrm{b}}$ Airlangga University School of Medicine and Dr. Soetomo General Hospital, Department of Urology, Surabaya, Indonesia
}

\section{A R T I C L E I N F O}

\section{Article history:}

Received 1 December 2014

Received in revised form 22 December 2015

Accepted 23 May 2016

Available online $\mathrm{xxxx}$

\section{Keywords:}

Urinary bladder

Lower urinary tract dysfunction

Brain bladder control

fMRI

Pet

Ultrasound

Magnetic resonance imaging

Cystography

\begin{abstract}
A B S T R A C T
The ability to store urine in the bladder and to void at an appropriate time depends on several complex mechanisms in the lower urinary tract (LUT) and its neural control. Normal LUT function requires coordination of the urinary bladder, urethra, pelvic floor, efferent and afferent neurons and specific spinal cord and brain areas. These structures can be visualised using different imaging modalities, such as ultrasound, X-ray and magnetic resonance imaging. The supraspinal neural control of the LUT can be studied using functional brain imaging. During the last two decades, the many technological improvements of these imaging techniques have increased our knowledge of voiding dysfunction.

Here, we review the different imaging modalities of the LUT and its neural control and discuss their importance for diagnosing and understanding voiding dysfunction.
\end{abstract}

(c) 2016 Published by Elsevier B.V.

\section{Contents}

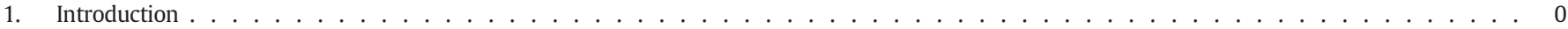

2. Imaging of the lower urinary tract to assess lower urinary tract dysfunction . . . . . . . . . . . . . . . . . . . . . . . . 0

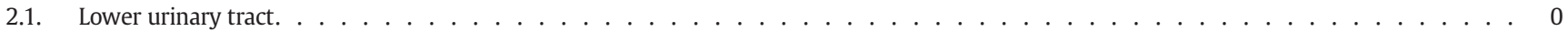

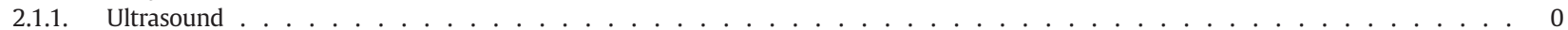

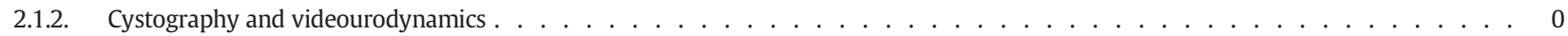

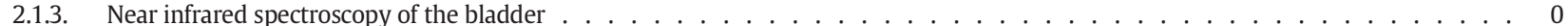

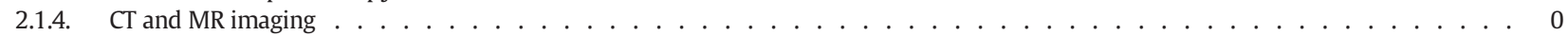

2.2. Prostate $\ldots$

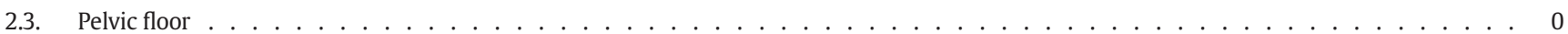

3. Imaging of the neural control of the lower urinary tract $\ldots \ldots \ldots \ldots$

3.1. What the brain can teach us about the bladder . . . . . . . . . . . . . . . . . . . . . . . . . . . . . . . . 0

3.2. Brain imaging and normal LUT function . . . . . . . . . . . . . . . . . . . . . . . . . . . . . . . 0

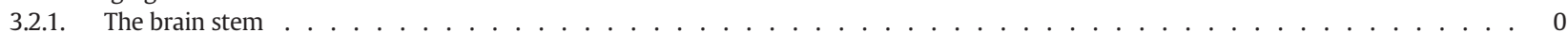

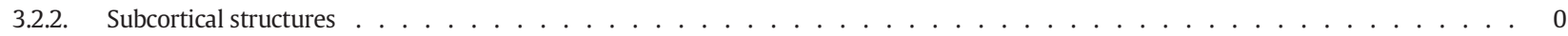

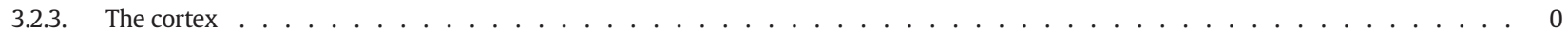

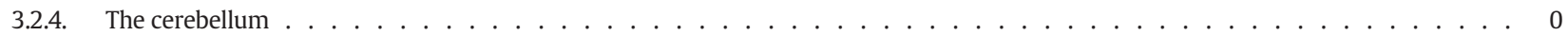

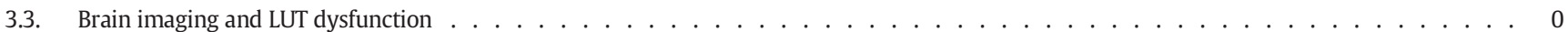

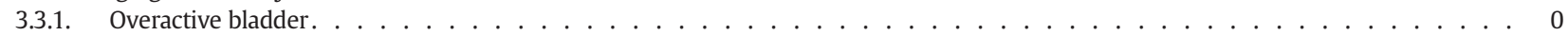

3.3.2. Fowler's syndrome. . . . . . . . . . . . . . . . . . . . . . . . . . . . . . . . 0

3.3.3. Parkinson's disease. . . . . . . . . . . . . . . . . . . . . . . . . . . . . . . . . . . . . . . . . . . . . . . . . . .

\footnotetext{
* Corresponding author at: Herestraat 49, 3000 Leuven, Belgium.

E-mail address: dirk.deridder@uzleuven.be (D. De Ridder).
} 


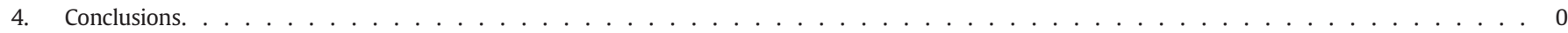

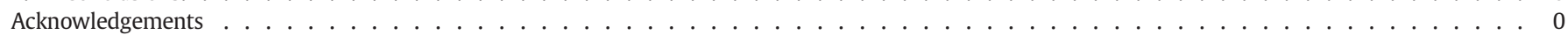

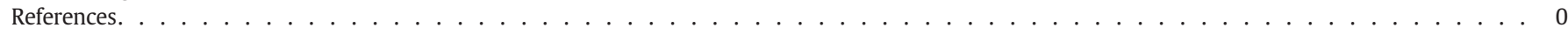

\section{Introduction}

The lower urinary tract (LUT) requires coordination of the urinary bladder, urethra, prostate, pelvic floor and specific spinal cord and brain areas. Different imaging modalities can be used to visualize these structures and are used to diagnose voiding dysfunction and study its pathophysiology.

Imaging modalities such as ultrasound (US), cystourethrography, computed tomography (CT) and magnetic resonance (MR) imaging are used to visualize the different structures of the LUT. In daily practice, US and cystourethrography are commonly used techniques to assess LUT dysfunction (LUTd). Although the use of MR imaging for voiding dysfunction remains limited, several clinical studies have already proven its potential in the diagnosis of stress urinary incontinence and benign prostatic hyperplasia (BPH). Imaging modalities of the LUT (i.e. bladder and urethra), prostate and pelvic floor and their application for diagnosing and understanding LUTd are discussed in the first part of this review (Table 1 ).

The LUT is also subjected to a complex neural control mechanism. In the last two decades it has become possible to study this supraspinal control of the LUT by means of positron emission tomography (PET) and functional magnetic resonance imaging (fMRI) of the brain. Although the number of studies investigating brain control of the LUT remains limited, they have already provided new insights into LUTd. Specific supraspinal changes are seen in women with detrusor overactivity, raising the question if this is more a dysfunction of the brain than of the bladder. Imaging of the supraspinal control mechanisms of the LUT and its importance for voiding dysfunction are reviewed in the second part of this article.

\section{Imaging of the lower urinary tract to assess lower urinary tract dysfunction}

\subsection{Lower urinary tract}

Although they are anatomically distinct structures, the bladder and urethra are functionally closely interrelated. Imaging of the bladder is often necessary to confirm clinical examination. Transabdominal US is an easy and cheap modality to assess structural abnormalities of the bladder, post-void residual urine (PVR), stone disease of the bladder or vesico-ureteral junction, inflammatory conditions and neoplasms. Retrograde and voiding cystography provide useful information to assess urogenital traumata and neurogenic bladder dysfunction. In the last two decades $\mathrm{CT}$ and MR imaging have proven their usefulness to assess voiding dysfunction, although their application in daily life practice for LUTd remains limited.

Clinical assessment of urethral symptoms is difficult and often requires further evaluation with imaging. Several urethral imaging modalities are currently available. Retrograde and voiding (cysto)urethrography provide information about luminal abnormalities of the urethra and are the most commonly used imaging modalities for patients with urethral abnormalities such as trauma, inflammation and strictures (Kim et al., 2007). In the last decade, cross-sectional imaging techniques such as US and MR have also shown their potential to study voiding dysfunction, congenital abnormalities, urethral diverticula, urethral carcinomas and periurethral cysts. Also endovaginal MR imaging of the female urethra offers reliable high resolution diagnostic imaging of these urethral abnormalities (Elsayes et al., 2006).

\subsubsection{Ultrasound}

In daily practice, US is frequently used to accurately measure the PVR that indicates how completely a patient empties his bladder. Elevated PVR occurs in patients with bladder outlet obstruction (BOO) and/or detrusor underactivity (Abrams and Griffiths, 1979). However, it is important to realize that elevated PVR is a poor predictor of urodynamically diagnosed BOO (Kranse and van Mastrigt, 2003).

Bladder wall thickness (BWT), measured by transabdominal US, might also be used as a diagnostic tool for BOO. It is important to note that BWT is dependent on bladder filling. BWT rapidly decreases during the first $250 \mathrm{ml}$ of bladder filling but, thereafter, remains more or less stable (Oelke et al., 2006). At a filling volume of $150 \mathrm{ml}$, a cut-off value of $5 \mathrm{~mm}$ appeared to be characteristic for the presence of obstruction (Manieri et al., 1998). Other studies showed similar results, although with other threshold values (Kessler et al., 2006). Another study by Blatt et al. could not demonstrate any differences in BWT in patients with BOO (Blatt et al., 2008). Detrusor wall thickness (DWT, bladder wall without the mucosal and subserosal layer) might be a more accurate measure for BOO. A DWT $>2 \mathrm{~mm}$ was reported in $94 \%$ of

Table 1

Overview of imaging modalities used to assess the different structures of the lower urinary tract and the possible diagnostic findings in patients with LUTd.

\begin{tabular}{|c|c|c|c|c|}
\hline \multirow[b]{2}{*}{ Imaging modality } & \multicolumn{4}{|l|}{ Imaging of } \\
\hline & Bladder & Urethra & Prostate & Pelvic floor \\
\hline Cystourethrography & $\begin{array}{l}\text { Bladder capacity, vesico-ureteral } \\
\text { reflux, contour, emptying } \\
\text { capability, detrusor sphincter } \\
\text { dyssynergia, tumor, calculi }\end{array}$ & $\begin{array}{l}\text { Detrusor sphincter dyssynergia, } \\
\text { stricture, fistula, trauma }\end{array}$ & - & - \\
\hline Cystocolpodefaecography & Cystocele & - & - & $\begin{array}{l}\text { Enterocele, rectocele, pelvic } \\
\text { floor descent }\end{array}$ \\
\hline Ultrasound & $\begin{array}{l}\text { PVR, bladder wall thickness, } \\
\text { detrusor strain, bladder weight }\end{array}$ & $\begin{array}{l}\text { Diverticulum, neoplasm, urethral } \\
\text { hypermobility }\end{array}$ & $\begin{array}{l}\text { Size, structure, resistive index of } \\
\text { capsular artery, presumed circle area } \\
\text { ratio, prostatic urethral angle, } \\
\text { intravesical prostatic protrusion }\end{array}$ & $\begin{array}{l}\text { Urethral hypermobility, } \\
\text { pelvic organ prolapse, } \\
\text { post-surgical evaluation }\end{array}$ \\
\hline MR imaging & Congenital abnormality, tumor & $\begin{array}{l}\text { Diverticulum, neoplasm, urethral } \\
\text { hypermobility, urethral muscle } \\
\text { volume, bladder neck funneling, } \\
\text { vesico-urethral angle }\end{array}$ & $\mathrm{BPH}$, prostate cancer, prostate cyst & $\begin{array}{l}\text { Pelvic organ prolapse, } \\
\text { disruption of urethral support } \\
\text { ligaments, asymmetric } \\
\text { pubococcygeus muscle }\end{array}$ \\
\hline CT imaging & Tumor & - & - & - \\
\hline NIRS & Oxygenation level of detrusor & - & - & - \\
\hline
\end{tabular}


men with signs of BOO on urodynamics (Oelke et al., 2007). Ultrasound measurement of BWT or DWT can also be used to investigate the response to medical or surgical treatment of BOO. Reduced BWT is observed after transvesical prostatectomy (Tubaro et al., 2001) and treatment with $\alpha-1$ receptor blockers (Egilmez et al., 2006). Azab et al. studied the correlation between BWT, international prostate symptoms score (IPSS) and voiding symptoms in patients with benign prostate hyperplasia (BPH) receiving $\alpha-1$ receptor blocker treatment (Salah Azab and Elsheikh, 2014). The authors observed a positive correlation between US findings and the scoring systems, which showed less BWT in patients receiving treatment. Although these results seem hopeful for a none-invasive diagnostic test for BOO, their use in clinical practice remains limited and methodological standardisation is needed (Parsons et al., 2011).

Assessment of BWT or DWT has also been extensively studied in paediatric voiding dysfunction. In 139 children a significant difference in DWT was found between children with normal urodynamics and children with non-neuropathic bladder/sphincter dysfunction, although it was difficult to establish a good cut-off value due to overlap of the measured values (Cvitkovic-Kuzmic et al., 2002). Therefore its use in daily practice for patient selection and differential diagnosis remains limited.

US can also be applied to estimate bladder weight. It is calculated from the thickness of the bladder wall and the intravesical volume assuming a spherical bladder. The sensitivity for BOO at a cut-off value of $35 \mathrm{~g}$ was $86 \%$ in a group of 65 men (Kojima et al., 1997). Other studies were not able to demonstrate a correlation between bladder weight and BOO (Almeida et al., 2011; Bright et al., 2011).

Idzenga et al. have shown the benefit of US to monitor the deformation in the detrusor muscle that may provide insight into the detrusor muscle's structural and dynamic properties related to bladder pressure (Idzenga et al., 2013). The authors demonstrated that US could be used to estimate strain in the detrusor muscle, which was positively correlated with the detrusor pressure. This result suggested that US could possibly be used to monitor detrusor muscle activity in a real time manner. This finding is important, since up to date pressure flow studies are the standard diagnostic urodynamic tests for lower urinary tract symptoms (LUTS) while US imaging could be used as a non-invasive tool option to replace this current method.

US imaging of the urethra allows imaging of different structural abnormalities such as urethral diverticulae and urethral neoplasms. The classic symptoms of urethral diverticula are post-voiding dribbling, urethral pain and dyspareunia (Romanzi et al., 2000). Multiplanar US allows imaging of the location, size, configuration and content of the diverticulum. Also the position of the diverticulum neck can be evaluated, which may be important for surgical planning. The presence of calculi in the sac can be evaluated with US (echogenic foci and acoustic shadow). All of these features are impossible to assess with conventional urethrography.

Urethral neoplasms are rare but can be the cause of otherwise unexplained voiding LUTs and haematuria. Leiomyoma and nephrogenic adenoma are benign tumours, whereas malignant tumours of the urethra include squamous cell carcinoma, transitional cell carcinoma and adenosarcoma. This differentiation can only be established with histopathological examination although US can reveal different characteristics of the different types of urethral neoplasms. Leiomyomas appear as well-defined, homogenous tumours with increased vascularity whereas, in general, carcinomas of the urethra appear as more heterogeneous lobulated, exophytic or deeply infiltrating lesions (Prasad et al., 2005).

In an experimental setting US might be used to assess the urethral vascularity in continent women using colour Doppler high frequency endovaginal ultrasonography (EVUS) in both transverse and sagittal planes (Lone et al., 2014). The authors demonstrated in 61 continent women that multiparous women had a significant reduction in the vascularity parameters compared to nulliparous women. This result can be used to inspire further study on urethral vascularity, to elucidate whether the results can be used to predict the event of urinary incontinence in women following vaginal delivery or multiparity.

The use of US imaging of the urethra in the preclinical setting has also been studied, but the applications for LUTd research are scarce. The use of high-frequency micro ultrasound ( $\mu \mathrm{US}$ ) as a novel method to assess urethral function in female rats has been introduced (Hakim et al., 2014). The authors showed that $\mu \mathrm{US}$ can be used to quantitatively measure the external urethral sphincter (EUS) opening and closing series (bursting pattern) in uninjured nulliparous and vaginal distension rat models, using predetermined parameters of intercontraction interval and total length of contraction. The authors concluded that $\mu \mathrm{US}$ could be beneficial to assess urethral function in translational studies, compared to the leak point pressure and EUS EMG that are currently being used.

\subsubsection{Cystography and videourodynamics}

Indications for simple cystography include assessment of anatomical integrity of the urethra and bladder, visualisation and preoperative planning for urethral strictures, postoperative control after urethral re-anastomosis in (cysto-) prostatectomy, after bladder augmentation or after repair of bladder rupture and many more. Voiding cystography is often performed in children with urinary tract infections and voiding abnormalities and should include assessment of masses, opaque calculi, bladder capacity, bladder contour, emptying capability and presence of reflux (Fernbach et al., 2000). Detrusor sphincter dyssynergia (DSD) in neurological patients can be diagnosed by cystourethrography showing a closed bladder neck during filling and subsequent dilated posterior urethra and bladder neck to the level of the external urethral sphincter during micturition (Bacsu et al., 2012). It is important to remark that the diagnosis of DSD in males by voiding cystography might be impaired due to anatomical BOO by the prostate.

However, cystography is probably used the most in combination with urodynamic evaluation of bladder function allowing both anatomic and functional assessment of the LUT. Especially patients with neurologic symptoms, a history of neurologic disease or congenital genitourinary anomalies benefit from videourodynamics (VUDS) (Marks and Goldman, 2014). Guidelines recommend the use of VUDS in the evaluation of patients with neurogenic LUTd (NLUTd) to assess vesicoureteral reflux or DSD. Also in younger patients without evident causes of obstructive voiding, VUDS can be used to study the function of the bladder neck, external sphincter and pelvic floor.

\subsubsection{Near infrared spectroscopy of the bladder}

Near infrared spectroscopy (NIRS) measures the level of oxyhaemoglobin and deoxyhaemoglobin in tissues. In BOO the workload of the detrusor muscle is increased, leading to a reduction in oxyhaemoglobin levels. An algorithm consisting of $\mathrm{Q}_{\max }$, PVR and NIRS was able to diagnose $86 \%$ correctly as obstructed (Macnab and Stothers, 2008). Several other studies have shown comparable results (Macnab et al., 2013; Yurt et al., 2012) but more recently Chung et al. showed a poor correlation between NIRS and urodynamics and another study has shown poor sensitivity and specificity for diagnosing detrusor overactivity (Chung et al., 2010; Mastoroudes et al., 2012). Several confounding factors can influence to results of NIRS including abdominal straining, motion artefacts, obesity and concomitant disease states such as vascular disease and renal failure.

\subsubsection{CT and MR imaging}

Cross-sectional imaging of the LUT allows further morphological and/or functional evaluation. CT imaging is often used in the staging of bladder cancer but its use for the assessment of LUTd remains limited. MR imaging, including functional MR urography can be used as a secondary imaging modality, especially for voiding dysfunction in 
paediatric urology (Darge et al., 2013). Primary conditions for MR imaging of the LUT are congenital abnormalities and bladder tumours.

In addition to US imaging, MR can be used to allow imaging of the position, size and content of urethral diverticulae. MR imaging can also reveal different characteristics of the different types of urethral neoplasms. As already mentioned, leiomyomas appear as welldefined, homogenous tumours with increased vascularity. At MR imaging these are iso- or hypointensive in T1-images and hyperintensive on T2-weighted images (Ikeda et al., 2001). In general carcinomas of the urethra appear as more heterogeneous lobulated, exophytic or deeply infiltrating lesions (Prasad et al., 2005).

Urethral hypermobility can be detected on MR (and also US) imaging and is associated with stress urinary incontinence in women. This urethral hypermobility is the result from weakening of supporting structures leading to downward displacement and rotation of the urethra (Macura et al., 2006). Urethral hypermobility is defined as a translation of $30^{\circ}$ or more from its initial axis during maximal straining and dynamic pelvic MR imaging is very helpful in establishing this diagnosis (Surabhi et al., 2013). In continent women the normal position of the urethra has been shown to be entirely retropubic whereas in stress-incontinent patients the lower segment of the urethra lies below the pubis (deSouza et al., 2002). Besides this hypermobility, other morphological abnormalities can be detected in women with stress urinary incontinence, which are discussed in the paragraph on the pelvic floor.

\subsection{Prostate}

The prostate is traditionally imaged by transrectal US (TRUS), mainly giving information about the size and structure of the prostate. Several new imaging parameters of the prostate like resistive index of the capsular artery, presumed circle area ratio, prostatic urethral angle and intravesical prostatic protrusion might be used to diagnose BOO; many studies have tried to find new non-invasive techniques to diagnose $\mathrm{BOO}$ because of the invasive aspect of pressure flow studies (Abdi et al., 2013).

An enlarged transitional zone of the prostate compresses the surgical capsule and hence will increase vascular resistance in the capsular artery. This can be measured with Doppler. This resistance index (=(peak systolic velocity-end diastolic velocity)/peak systolic velocity) with a cut-off value of $>0,75$ seems to be a more reliable predictor of BOO than international prostate symptom score (IPSS) and PVR (Shinbo and Kurita, 2011; Shinbo et al., 2010). However, this technique still needs to be further validated in the light of concomitant vascular disease, diabetes mellitus, effect of heart rate and the effect of patient positioning.

If the prostate enlarges, it will become more circle-shaped because of the limited elastic capacity of the prostatic capsule. The presumed circle area ratio is calculated where the horizontal section of the prostate in TRUS shows the biggest surface. The ratio of this surface to the presumed circle with the same circumference will then be calculated. A presumed circle area ratio $>0,9$ correlates with symptoms scores after adjusting for age and prostate volume (St Sauver et al., 2009).

Some studies have emphasized the role of the prostatic angle in LUTS (Cho et al., 2008). The prostatic urethral angle is the angle between the prostatic and membranous urethra in TRUS. Studies have stated that a higher prostatic urethral angle is related with LUTS (Park et al., 2012) and higher BOO index (Ku et al., 2010). Before this parameter can be used in daily practice it should be further validated in well designed, control matched prospective studies.

Another parameter that can be assessed with US is intravesical prostatic protrusion (IPP). Enlargement of the median lobe of the prostate can increase bladder outlet resistance. IPP aims to measure the distance between the tip of the prostate median lobe and the bladder neck using tansabdominal ultrasound. The bladder should be filled in between
150 and $250 \mathrm{ml}$, because IPP is known to decrease with increasing bladder volume (Yuen et al., 2002). IPP distance can be divided into three grades: 0-4,9 mm (grade I), 5-10 mm (grade II) and $>10 \mathrm{~mm}$ (grade III). According to different studies IPP grade III correctly identifies 71-94\% of obstructed patients (Chia et al., 2003; Lim et al., 2006). IPP can also be used to predict recurrence after acute urinary retention and medical treatment; $75 \%$ of the patients with IPP grade I and II were free of recurrence compared with only $13 \%$ of grade III IPP patients (Mariappan et al., 2007).

3D-Transrectal US of the prostate provides excellent resolution of the prostate gland anatomy and is able to differentiate between the central and transitional zone of the prostate, which is not possible with conventional TRUS. Nodular balance and type (stromal vs. glandular) were correlated with symptom severity in 113 patients before transurethral resection of the prostate (Elwagdy et al., 2008).

MR imaging of the prostate is increasingly used in the diagnosis and staging of prostate cancer but its use for LUTD remains limited. Kershaw et al. have evaluated microvascular and relaxation parameters of the prostate in 13 patients with BPH. They concluded that they could measure these specific parameters for BPH precisely and that they were highly reproducible (Kershaw et al., 2009). Another study compared diffusion-weighted imaging of the normal prostate, prostate cysts, $\mathrm{BPH}$ nodules and prostate cancer en found significant differences, useful for differential diagnosis (Ren et al., 2008). The use of MR imaging in $\mathrm{BPH}$ patients in daily practice is limited by its high cost and limited availability.

\subsection{Pelvic floor}

Various modalities allow imaging of the structures of the pelvic floor. Imaging of the pelvic floor is becoming more important as our understanding of pelvic floor dysfunction and treatment options increase. Common symptoms due to pelvic floor dysfunction are faecal incontinence, pelvic organ prolapse and urinary incontinence. Imaging techniques that are currently used to study pelvic floor dysfunction include US imaging, MR imaging and cystocolpodefaecography (CCD).

Ultrasound can be used to image the different structures of the pelvic floor, pathological features, as well as meshes, slings and other implants (Dietz and Wilson, 2004). US of the pelvic floor has a wide range of indications including recurrent urinary tract infections, stress incontinence, prolapse, faecal incontinence and post-surgical evaluation of transvaginal tapes and sacral colposuspension (Ahmad et al., 2015). As already reviewed above urethral hypermobility is a common finding in the assessment of stress urinary incontinence (Prasad et al., 2005). US is an excellent imaging modality to asses bladder neck descent to measure urethral mobility (Wieczorek et al., 2011). 3D US assessment gives information about the urethral position in the different planes, giving more complete diagnostic information (Santoro et al., 2009). US imaging of the middle and posterior compartment is able to visualize uterine prolapse, rectocele, rectal intussusception and enterocele (Dietz, 2010).

MR is also an excellent imaging modality for the pelvic floor, although its clinical use is often limited due to its limited availability and high costs. To characterize pelvic organ prolapse MR imaging can be used, although the lack of standardisation and the high number of different reference lines is a problem (Ahmad et al., 2015). From a set reference point organ prolapse during straining in the three compartments can be visualised and staged. An advantage of dynamic MR imaging is that movement of pelvic organs can be visualised during straining and contraction. MR imaging in women with stress urinary incontinence can detect different abnormalities which either are related to urethral sphincter deficiency or related to defects of the urethral support ligaments and urethral hypermobility (Macura et al., 2006). The volume of the urethral muscle can be determined on MR imaging and thinning of the striated muscle has been reported in patients with stress incontinence (Athanasiou et al., 1999). Also funneling of the urethra (widening 
of the urethra at the proximal neck) and disruption of the urethral support ligaments are frequently visualised abnormalities in patients with stress incontinence (Macura et al., 2006). Furthermore lateral deviation of the pubococcygeus muscle in combination with thinning has been shown in patients with stress incontinence (Kirschner-Hermanns et al., 1993). An increased versicourethral angle, which is the angle between the axis of the urethra and the posterior bladder base, is also reported to be more frequent in patients with stress urinary incontinence (Kim et al., 2003).

Cystocolpodefaecography (CCD), in which bladder, urethra, vagina, rectum and bowel are imaged with barium contrast, is the current gold standard for diagnosis of prolapse of the posterior compartment (Steensma et al., 2010). CCD is commonly used to detect pelvic floor changes caused by excessive straining such as rectocele, enterocele, pelvic floor descent and intussusception (Maglinte et al., 2011).

\section{Imaging of the neural control of the lower urinary tract}

\subsection{What the brain can teach us about the bladder}

The LUT is regulated by a complex neural control mechanism. The direction of this communication is not only in a one-way (efferent) direction from central nervous system (CNS) to the LUT, but afferent signalling pathways, originating in the urothelium and small afferent nerves in the bladder wall, are also continuously giving input into the central nervous system. Growing evidence suggests that these afferent signals and their central processing play an important role in normal
LUT function and in the pathogenesis of functional LUT diseases, such as overactive bladder (OAB) (Kanai and Andersson, 2010).

In the last two decades it has become possible to study this supraspinal control of the LUT directly by means of positron emission tomography (PET) and functional magnetic resonance imaging ( $\mathrm{fMRI}$ ) of the brain. PET requires the injection of a radioactive isotope that will accumulate in a metabolically active brain region while fMRI measures the changing proportion of oxygenated and deoxygenated haemoglobin in activated brain areas. Both methods provide complementary functional information about the brain. PET is not able to detect rapid changes in brain metabolism but is very sensitive for small changes in neural activity while fMRI has an excellent spatial and temporal resolution but requires multiple runs of the same event to increase signal-to-noise ratio (Catana et al., 2012; Mier and Mier, 2015). Near Infrared Spectroscopy (NIRS) is another technique that is sporadically used to study supraspinal control of the bladder. It takes advantage of the changing concentrations of haemoglobin in the cerebral cortex, but its main disadvantage is the very limited resolution for deeper brain structures since it can only accurately measure to a depth of $1 \mathrm{~cm}$ beneath the skull (Matsumoto et al., 2009).

In the last two decades these different brain imaging techniques have been widely spread and optimized, providing a vast amount of literature about nearly every human cortical function (Fig. 1). Unfortunately, the number of studies that have looked into brain control of bladder function is until now still relatively small, but nevertheless these studies have provided us with valuable new insights into LUT (patho)physiology. It must be remarked that most of these studies use

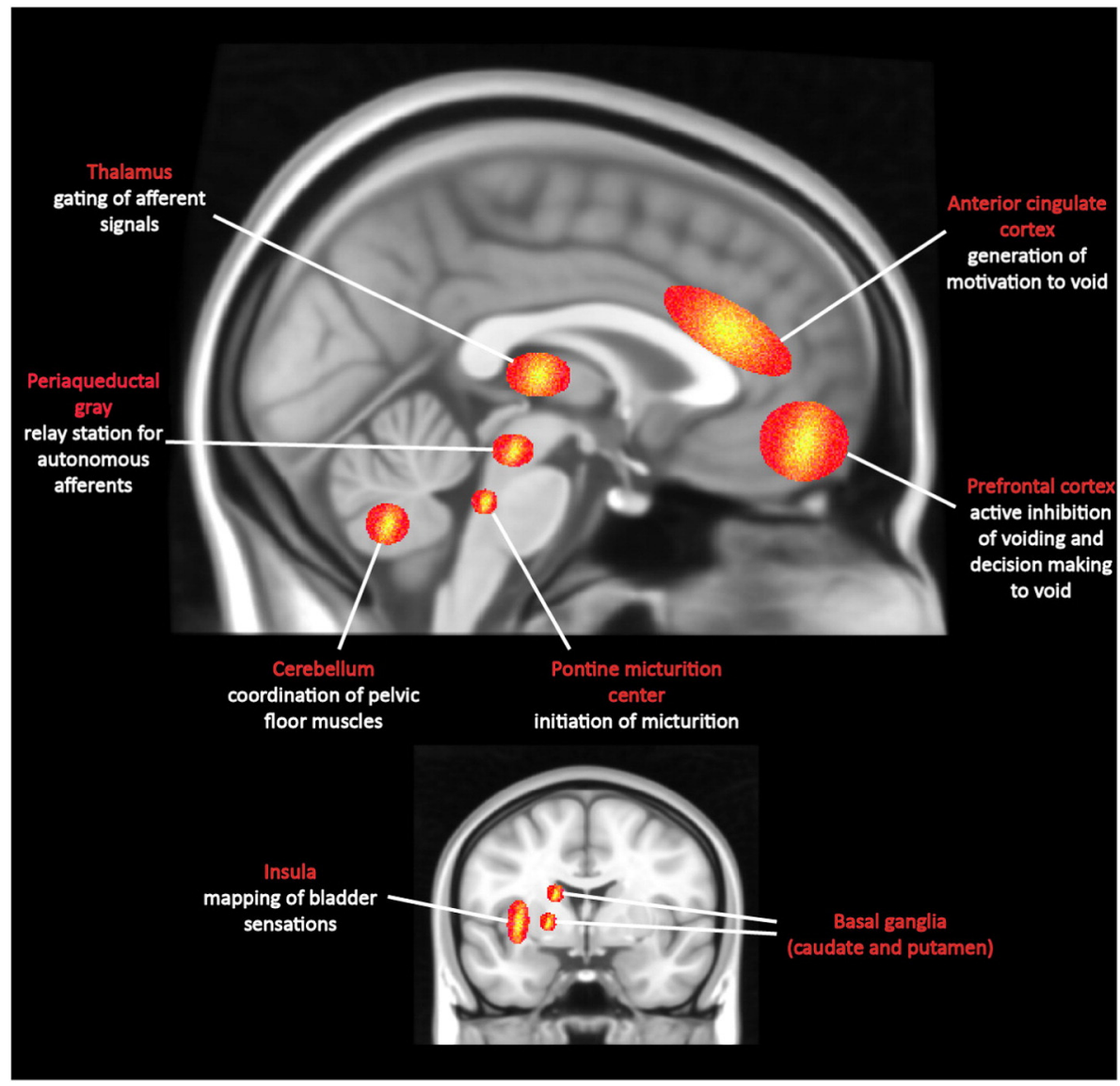

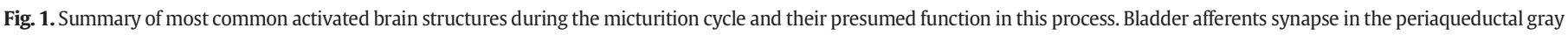

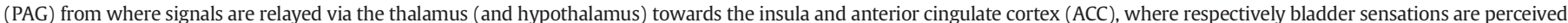

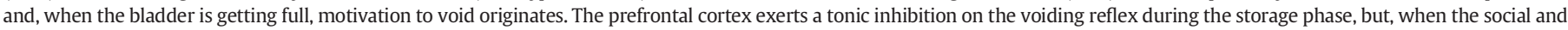

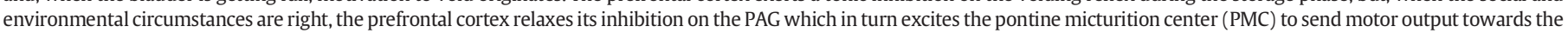
sacral spinal cord and initiate voiding. 
Table 2

Summary of functional brain imaging studies applied to neural control of the lower urinary tract.

\begin{tabular}{|c|c|c|c|}
\hline Study & Modality & Detection of brain metabolism during & Patients \\
\hline Fukuyama et al. (1996) & SPECT & Voiding & Normal men \\
\hline Blok et al. (1997) & PET & Voiding & Normal men $(n=17)$ \\
\hline Blok et al. (1998) & PET & Voiding & Normal women $(n=18)$ \\
\hline Nour et al. (2000) & PET & Voiding and bladder filling & Normal men $(n=12)$ \\
\hline Athwal et al. (2001) & PET & Bladder filling & Normal men $(n=11)$ \\
\hline Matsuura et al. (2002) & PET & Bladder filling and intravesical ice water & Normal men $(n=17)$ \\
\hline Dasgupta et al. (2005) & PET & During bladder filling after sacral neuromodulation & Patients with Fowler's syndrome $(n=8)$ and healthy controls $(n=8)$ \\
\hline Zhang et al. (2005) & fMRI & Bladder filling and pelvic floor contraction & Normal men $(n=12)$ \\
\hline Griffiths et al. (2005) & fMRI & Bladder filling & Patients with $\mathrm{OAB}(n=6)$ and healthy controls $(n=6)$ \\
\hline Kuhtz-Buschbeck et al. (2005) & fMRI & Bladder filling and pelvic floor contraction & Normal women $(n=22)$ \\
\hline Seseke et al. (2006) & fMRI & Bladder filling and pelvic floor contraction & Normal women $(n=11)$ \\
\hline Kitta et al. (2006) & PET & Detrusor overactivity & Patients with Parkinson's disease $(n=9)$ \\
\hline Yin et al. (2006) & SPECT & Bladder filling & Normal men $(n=15)$ \\
\hline Herzog et al. (2006) & PET & Bladder filling during subthalamic stimulation & Patients with Parkinson's disease $(n=11)$ \\
\hline \multicolumn{4}{|l|}{ Herzog et al. (2008) } \\
\hline Griffiths et al. (2007) & fMRI & Bladder filling & Women with urge incontinence $(n=11)$ and healthy controls $(n=10)$ \\
\hline \multicolumn{4}{|l|}{ Tadic et al. (2008) } \\
\hline Mehnert et al. (2008) & fMRI & Bladder filling and clitoral nerve stimulation & Normal women $(n=8)$ \\
\hline Seseke et al. (2008) & fMRI & Bladder filling and pelvic floor contraction & Normal men $(n=12)$ \\
\hline Kuhtz-Buschbeck et al. (2009) & fMRI & Different bladder sensations & Normal men $(n=16)$ and women $(n=17)$ \\
\hline Griffiths et al. (2009) & fMRI & Bladder filling & Normal women $(n=10)$ \\
\hline Tai et al. (2009) & fMRI & Bladder filling and isovolumetric contraction in rats & Animal study: rats \\
\hline Zempleni et al. (2010) & fMRI & Bladder filling and pudendal nerve stimulation & Patients with incomplete spinal cord injury $(n=8)$ \\
\hline Kavia et al. (2010) & fMRI & Bladder filling after sacral neuromodulation & Patients with Fowler's syndrome $(n=6)$ \\
\hline Tadic et al. (2010a,b) & fMRI & Bladder filling & Female patients $>60$ years with urge incontinence $(n=25)$ \\
\hline Mehnert et al. (2011) & fMRI & Bladder filling and bladder cold sensation & Normal women $(n=14)$ \\
\hline Komesu et al. (2011) & fMRI & Bladder filling & Patients with $\mathrm{OAB}(n=5)$ and healthy controls $(n=5)$ \\
\hline Tadic et al. (2012) & fMRI & Bladder filling & Older women with $\mathrm{OAB}(n=30)$ \\
\hline Krhut et al. (2013) & fMRI & Bladder filling and pelvic floor contraction & Normal women $(n=23)$ \\
\hline Nardos et al. (2013) & Rs-fcMRI & Bladder filling & Normal women $(n=20)$ \\
\hline Tadic et al. (2013) & fMRI & Bladder filling & Women $>65$ years $(n=11)$ \\
\hline Shy et al. (2014) & fMRI & Bladder filling & Normal women $(n=13)$ \\
\hline Wong et al. (2014) & fMRI & Bladder filling and isovolumetric contraction in rats & Animal study: spinal cord transected rats \\
\hline
\end{tabular}

different study designs and paradigms, which can be confusing and makes it harder to draw strong conclusions about the brain control of the lower urinary tract. For the sake of brevity, not all of these studies and their specific paradigms will be discussed in detail in this review but an overview of the studies and their specific study designs is provided in Table 2. (See Table 2.)

\subsection{Brain imaging and normal LUT function}

\subsubsection{The brain stem}

The first functional brain imaging study in men, which examined neural mechanisms of micturition using SPECT, revealed activation of the upper pons region (Fukuyama et al., 1996). Activation of the pontine tegmentum during voiding was soon afterwards confirmed by Blok et al., using PET imaging of the brain in healthy male volunteers (Blok et al., 1997). Already decades before these studies, lesion and electrophysiological experiments in the cat and rat (Barrington, 1925; Loewy et al., 1979) had shown that a group of neurons in the dorsomedial pons was associated with micturition but brain imaging studies provided the first strong evidence that such neurons also existed in the human pons. This region is generally referred to as pontine micturition centre (PMC) or Barrington's nucleus (named after the surgeon who already described its importance in voiding in 1925) (Barrington, 1925). Activation of the PMC results in the initiation of bladder detrusor contraction and relaxation of the urethral sphincter, while it is actively inhibited during the storage of urine (Griffiths and Tadic, 2008). Evidence that this structure is indeed important for voiding has later on been confirmed by several brain imaging studies, both in human (Athwal et al., 2001; Dasgupta et al., 2005; Griffiths et al., 2005, 2007; Kitta et al., 2006; Kuhtz-Buschbeck et al., 2005; Matsuura et al., 2002; Seseke et al., 2006; Shy et al., 2014) and rodents (Tai et al., 2009).

The peri-aqueductal gray (PAG) has been found activated in nearly every PET (Athwal et al., 2001; Blok et al., 1998; Dasgupta et al., 2005; Matsuura et al., 2002) or fMRI study (Griffiths et al., 2005, 2007;
Kuhtz-Buschbeck et al., 2005; Seseke et al., 2006; Zhang et al., 2005). Recently two groups have even reported PAG activation during bladder filling detected by fMRI in rats (Tai et al., 2009; Wong et al., 2014). The PAG is traditionally described as a relay station where autonomous afferents from the bladder and other pelvic organs, ascending via the spinal cord, synaps and signals are further conveyed towards higher brain structures: ascending PAG outputs include amygdala, hypothalamus and thalamus (Craig, 2003). Furthermore the PAG also receives input from forebrain regions including the insula, anterior cingulate cortex (ACG), amygdala and several prefrontal cortical regions (Mantyh, 1983). The PAG also has an important efferent function, transmitting signals via the PMC towards the sacral spinal cord (Blok and Holstege, 1994).

The involvement of the L-region or pontine storage centre (lateral pontine tegmentum) in micturition control is controversial. The theoretical basis for the L-region comes from an experimental animal study in which one cat was incontinent after damaging this region (Griffiths, 2002). Later on some brain imaging studies in human have reported activity in this area in subjects that were unable to void in the scanner (Blok et al., 1997; Kuhtz-Buschbeck et al., 2007; Seseke et al., 2006).

\subsubsection{Subcortical structures}

The posterior hypothalamus is, together with the PAG, the only brain structure that has direct afferent access to the PMC (Kuipers et al., 2006). Although other brain structures can influence the control of the LUT, these signals are thus obligatory to pass via the hypothalamus or PAG to reach the PMC for initiation of voiding. Hence, the hypothalamus may permit the forebrain to influence the voiding reflex. The hypothalamus plays a role in many homeostatic processes such as sleep and fluid balance. Some brain imaging studies have shown this hypothalamic involvement during bladder filling and voiding (Athwal et al., 2001; Griffiths et al., 2005; Tai et al., 2009).

The thalamus gates information of almost every sensory pathway, including afferent signals from the LUT (Yingling and Skinner, 1976). Consistent with this concept activation of the thalamus was detected 
in several studies during storage of urine (Griffiths et al., 2005, 2007; Matsuura et al., 2002; Shy et al., 2014). The thalamus consists of different nuclei that have direct connections with different cortical regions, including the prefrontal cortex, and the PAG (Mantyh, 1983; Vertes, 2001), making this structure important in relaying information from the bladder to the "decision-making" cortex and back again.

The nuclei that form the basal ganglia also seem to be involved in controlling micturition. The basal ganglia comprise the striatum (caudate and putamen), globus pallidus, substantia nigra and the subthalamic nucleus. These structures are mostly associated with voluntary control of motion and dopamine depletion in the striatum leads to Parkinson's disease (PD), which is not only characterized by motor symptoms but also by bothersome urinary complaints such as urinary urgency and incontinence (Winge and Fowler, 2006). How brain control of the bladder is affected in patients with PD is reviewed further on in this article. Electrophysiological studies have also shown a correlation between firing in the striatum and bladder relaxation and contraction (Yamamoto et al., 2009). Different imaging studies have detected activation in the basal ganglia (mostly the striatum) during the storage of urine (Matsuura et al., 2002; Nardos et al., 2013; Tadic et al., 2010b; Tai et al., 2009; Wong et al., 2014), but the exact role of these structures in the neural control of the LUT remains elusive.

Traditionally the limbic system is perceived as the area involved in regulating emotions, memory and sexual arousal, although brain imaging studies have demonstrated that certain nuclei also participate in controlling the LUT. The limbic system consists of diverse structures including the amygdala, the hippocampus and the cingulate and parahippocampal gyrus (Griffiths and Fowler, 2013). A single paper reports activation of the left amygdala/parahippocampal gyrus in response to fluid infusion at low bladder volumes (Griffiths and Tadic, 2008), although this was not confirmed by other studies. Hippocampal activation was detected during bladder contractions by fMRI in rats (Tai et al., 2009; Wong et al., 2014) while in women with OAB deactivation of the parahippocampal gyrus was seen during bladder filling (Tadic et al., 2010b). These data indicate that the amygdala and hippocampus play a role in bladder control but elucidation of their exact function awaits further research.

\subsubsection{The cortex}

The insula or insular cortex, and island of cortex in between the frontal and the temporal lobe, is perceived as the cortical representation of homeostatic afferent activity representing the physiological condition of all tissues in the body (Craig, 2003). It is the endpoint of the "interoceptive system" which guides autonomic motor control and triggers feelings such as hunger, thirst and visceral sensations, including the feeling of bladder fullness. Afferents enter via the PAG and hypothalamus, relay in the thalamus and finally converge in the insula. Insular activation becomes stronger with increasing bladder filling (Griffiths et al., 2007) and activation of the insula during bladder filling has been detected in many PET (Kitta et al., 2006; Matsuura et al., 2002) and fMRI studies (Griffiths et al., 2005, 2007; Komesu et al., 2011; Kuhtz-Buschbeck et al., 2005; Tadic et al., 2013), confirming that this area is indeed involved in the mapping of afferent signals from the LUT.

Often insular activation is reported together with activation of the anterior cingulate cortex (ACC). Activation of the ACC is associated with the generation of motivation; "homeostatic emotions" such as hunger, thirst or the feeling of bladder fullness drive certain behavioural patterns like eating, drinking or voiding (Craig, 2003). Hence, the ACC is considered important for the emotional and motivational aspects of micturition. Although the exact location of activation varies in the different studies, almost every functional brain imaging study has detected some part of the cingulate cortex to be activated during bladder filling (Athwal et al., 2001; Griffiths et al., 2007; Matsuura et al., 2002; Nardos et al., 2013; Shy et al., 2014; Tadic et al., 2010a).

The prefrontal cortex (PFC) is the area responsible for cognition and planning of complex behaviour and is therefore involved in the conscious and social control of the LUT (Wood and Grafman, 2003). It is well known from patients with frontal lobe lesions that the PFC is important for normal LUT control (Nathan and Andrew, 1964). Activation of various areas in the PFC, mostly the medial and orbitofrontal cortex, has been detected during both voiding (Blok et al., 1997; Nour et al., 2000) and filling of the bladder (Matsuura et al., 2002; Shy et al., 2014; Tadic et al., 2008). NIRS has found similar regions to be activated during bladder filling (Farag et al., 2011; Matsumoto et al., 2009, 2011; Sakakibara et al., 2010). As already remarked above, the PFC has multiple connections with other regions involved in the bladder control, including the ACG, hypothalamus and PAG. It is the site of convergence of information about the external environment and (social) cognition. Exactly how this area is involved in LUT control is not fully understood, but its importance is hard to underestimate. Probably, the role of the PFC is dual: suppression of excitatory signals towards the PMC during bladder filling and, depending on the social context, decision making to void by initiation of the micturition reflex.

\subsubsection{The cerebellum}

Activation of regions in the cerebellum during the micturition cycle has been reported by several studies but their exact meaning has not been thoroughly studied (Griffiths et al., 2005; Matsuura et al., 2002; Nour et al., 2000; Zhang et al., 2005). Like the basal ganglia, the cerebellum is traditionally perceived as a brain structure important for the coordination of voluntary movement and is therefore also involved in the relaxation and contraction of the pelvic floor muscles (Seseke et al., 2006).

\subsection{Brain imaging and LUT dysfunction}

\subsubsection{Overactive bladder}

Mainly the Pittsburgh group has studied brain responses to repetitive bladder infusion in a cohort of older urge incontinent women. In subjects with known detrusor overactivity a full bladder provoked exaggerated responses in many of the areas discussed above, including insula and ACC, but responses in the orbitofrontal cortex were abnormally weak (Griffiths et al., 2005). In another study disproportionate activation of the ACC during bladder filling seemed very characteristic for people with urge incontinence (Griffiths et al., 2007). This increased activation of the ACC in OAB patients was afterwards confirmed in a fMRI study from another group (Komesu et al., 2011). These findings suggest that in $\mathrm{OAB}$ patients some degree of aberrant processing of afferent signals from the LUT occurs, which is characterized by an abnormal weak response of the orbitofrontal cortex and an exaggerated activation in other brain regions, including insula and ACC, which could explain the abnormal sensation of urgency (Griffiths and Tadic, 2008). Also several NIRS studies have evaluated cortical function in patients with $\mathrm{OAB}$. Faraq et al. concluded that sensitivity and specificity of deoxyhemoglobin curves measured by NIRS for detrusor overactivity were both around $80 \%$ and, thus, that NIRS has the potential to be a non-invasive diagnostic method for detrusor overactivity (Farag et al., 2011). Also, NIRS detected increased activation in the PFC of OAB patients treated with the antimuscarinic agents Imidafenacin and Tolterodine, probably representing a secondary phenomenon since the drugs barely penetrate the blood-brain barrier (Sakakibara et al., 2013, 2014). Changes in the supraspinal control of the LUT are thus associated with $\mathrm{OAB}$ but whether these differences in brain metabolic activity can be causative for the symptoms or are secondary to the LUTd remains to be established.

\subsubsection{Fowler's syndrome}

Two studies explored brain control of the LUT in women with urinary retention due to sphincter overactivity (Fowler's syndrome) and the influence of sacral neuromodulation (SNM) on this pathology. Dasgupta et al. showed that brainstem activity was absent and limbic cortical activity was enhanced during bladder fullness in patients with 
Fowler's syndrome. Following SNM however, a normal pattern of brain activity, including PAG activation, and normal bladder sensations were restored (Dasgupta et al., 2005). A more recent study, using fMRI, showed widespread deactivations during the filling phase, a finding which also partially normalised after SNM (Kavia et al., 2010). These studies support the hypothesis that SNM blocks the inhibition of afferent signalling from the LUT, which occurs in patients suffering from Fowler's syndrome, and thus gives rise to normal bladder sensations and restores normal voiding.

\subsubsection{Parkinson's disease}

Patients with Parkinson's disease (PD) often suffer urinary urgency and frequency, induced by detrusor overactivity (Winge and Fowler, 2006). Brain activation in PD patients during bladder filling seems not to differ strongly from results in healthy volunteers (Kitta et al., 2006), although no activation of the PMC was detected. Another study showed that deep brain stimulation of the subthalamic nucleus modulates neural activity in the posterior thalamus and insula of these patients and consequently improves bladder dysfunction (Herzog et al., 2008). Deep brain stimulation possibly could improve the sensory gating process in PD patients and thus regulate afferent signal processing in the insula and ACC.

\section{Conclusions}

Imaging techniques can contribute greatly to our current understanding of lower urinary tract dysfunction. A variety of imaging modalities is available to visualize the bladder, urethra, prostate and pelvic floor. These techniques can be used to confirm clinical diagnosis, as an alternative diagnostic method to replace invasive urodynamic studies or to enhance our current knowledge of LUT pathophysiology. Imaging of the supraspinal neural control of the LUT is currently used in an experimental setting but has to potential to reveal important new insights into the pathophysiology of voiding dysfunction.

\section{Acknowledgements}

Dirk De Ridder is a senior clinical researcher of the FWO Vlaanderen. This work was supported by grants from the Belgian Federal Government (IUAP P7/13) and the Research Council of the KU Leuven (PF-TRPLe).

\section{References}

Abdi, H., Kazzazi, A., Bazargani, S.T., Djavan, B., Telegrafi, S., 2013. Imaging in benign prostatic hyperplasia: what is new? Curr. Opin. Urol 23, 11-16. http://dx.doi.org/10. 1097/MOU.0b013e32835abd91.

Abrams, P.H., Griffiths, D.J., 1979. The assessment of prostatic obstruction from urodynamic measurements and from residual urine. Br. J. Urol 51, 129-134.

Ahmad, A.N., Hainsworth, A., Williams, A.B., Schizas, A.M.P., 2015. A review of functional pelvic floor imaging modalities and their effectiveness. Clin. Imaging 39, 559-565. http://dx.doi.org/10.1016/j.clinimag.2015.02.013.

Almeida, F.G., Freitas, D.G., Bruschini, H., 2011. Is the ultrasound-estimated bladder weight a reliable method for evaluating bladder outlet obstruction? BJ. Int. 108, 864-867. http://dx.doi.org/10.1111/j.1464-410X.2010.09881.x.

Athanasiou, S., Khullar, V., Boos, K., Salvatore, S., Cardozo, L., 1999. Imaging the urethral sphincter with three-dimensional ultrasound. Obstet. Gynecol 94, 295-301.

Athwal, B.S., Berkley, K.J., Hussain, I., Brennan, A., Craggs, M., Sakakibara, R., Frackowiak, R.S., Fowler, C.J., 2001. Brain responses to changes in bladder volume and urge to void in healthy men. Brain 124, 369-377.

Bacsu, C.-D., Chan, L., Tse, V., 2012. Diagnosing detrusor sphincter dyssynergia in the neurological patient. BJ. Int. 109 (Suppl. 3), 31-34. http://dx.doi.org/10.1111/j.1464410X.2012.11042.x.

Barrington, F.J.F., 1925. The effect of lesions of the hind- and mid-brain on micturition in the cat. Exp. Physiol 15, 81-102.

Blatt, A.H., Titus, J., Chan, L., 2008. Ultrasound measurement of bladder wall thickness in the assessment of voiding dysfunction. J. Urol 179, 2275-2278. http://dx.doi.org/10. 1016/j.juro.2008.01.118 discussion 2278-9.

Blok, B.F., Holstege, G., 1994. Direct projections from the periaqueductal gray to the pontine micturition center (M-region). An anterograde and retrograde tracing study in the cat. Neurosci. Lett 166, 93-96.

Blok, B.F., Willemsen, A.T., Holstege, G., 1997. A PET study on brain control of micturition in humans. Brain 120 (Pt 1), 111-121.
Blok, B.F., Sturms, L.M., Holstege, G., 1998. Brain activation during micturition in women. Brain 121 (Pt 11), 2033-2042.

Bright, E., Pearcy, R., Abrams, P., 2011. Ultrasound estimated bladder weight in men attending the uroflowmetry clinic. Neurourol. Urodyn 30, 583-586. http://dx.doi. org/10.1002/nau.21049.

Catana, C., Drzezga, A., Heiss, W.-D., Rosen, B.R., 2012. PET/MRI for neurologic applications. J. Nucl. Med 53, 1916-1925. http://dx.doi.org/10.2967/jnumed.112.105346.

Chia, S.J., Heng, C.T., Chan, S.P., Foo, K.T., 2003. Correlation of intravesical prostatic protrusion with bladder outlet obstruction. BJ. Int. 91, 371-374.

Cho, K.S., Kim, J., Choi, Y.D., Kim, J.H., Hong, S.J., 2008. The overlooked cause of benign prostatic hyperplasia: prostatic urethral angulation. Med. Hypotheses 70, 532-535. http://dx.doi.org/10.1016/j.mehy.2007.07.012.

Chung, D.E., Lee, R.K., Kaplan, S.A., Te, A.E., 2010. Concordance of near infrared spectroscopy with pressure flow studies in men with lower urinary tract symptoms. J. Urol 184 2434-2439. http://dx.doi.org/10.1016/j.juro.2010.08.027.

Craig, A.D., 2003. Interoception: the sense of the physiological condition of the body. Curr. Opin. Neurobiol 13, 500-505.

Cvitkovic-Kuzmic, A., Brkljacic, B., Ivankovic, D., Grga, A., 2002. Ultrasound assessment of detrusor muscle thickness in children with non-neuropathic bladder/sphincter dysfunction. Eur. Urol 41, 214-218 discussion 218-9.

Darge, K., Higgins, M., Hwang, T.J., Delgado, J., Shukla, A., Bellah, R., 2013. Magnetic resonance and computed tomography in pediatric urology: an imaging overview for current and future daily practice. Radiol. Clin. N. Am 51, 583-598. http://dx.doi. org/10.1016/j.rcl.2013.03.004.

Dasgupta, R., Critchley, H.D., Dolan, R.J., Fowler, C.J., 2005. Changes in brain activity following sacral neuromodulation for urinary retention. J. Urol 174, 2268-2272. http://dx.doi.org/10.1097/01.ju.0000181806.59363.d1.

deSouza, N.M., Daniels, O.J., Williams, A.D., Gilderdale, D.J., Abel, P.D., 2002. Female urinary genuine stress incontinence: anatomic considerations at MR imaging of the paravaginal fascia and urethra initial observations. Radiology 225, 433-439. http://dx.doi.org/10.1148/radiol.2252011347.

Dietz, H.P., 2010. Pelvic floor ultrasound: a review. Am. J. Obstet. Gynecol 202, 321-334 http://dx.doi.org/10.1016/j.ajog.2009.08.018.

Dietz, H.P., Wilson, P.D., 2004. The "iris effect": how two-dimensional and threedimensional ultrasound can help us understand anti-incontinence procedures Ultrasound Obstet. Gynecol 23, 267-271. http://dx.doi.org/10.1002/uog.985.

Egilmez, T., Pourbagher, M.A., Guvel, S., Kilinc, F., Turunc, T., Ozkardes, H., 2006. Effects of selective alpha-1-adrenergic receptor blockers on bladder weight. Urol. Int. 76 42-50. http://dx.doi.org/10.1159/000089734.

Elsayes, K.M., Mukundan, G., Narra, V.R., Abou El Abbass, H.A., Prasad, S.R., Brown, J.J. 2006. Endovaginal magnetic resonance imaging of the female urethra. J. Comput. Assist. Tomogr 30, 1-6.

Elwagdy, S., Samy, E., Sayed, M., Gamal, A.-H., 2008. Benign prostatic hyperplasia: clinical benefits on Three-Dimensional Ultrasound eXtended Imaging (3D-XI). Int. J. Urol 15 332-339. http://dx.doi.org/10.1111/j.1442-2042.2008.01988.x.

Farag, F.F., Martens, F.M., D'Hauwers, K.W., Feitz, W.F., Heesakkers, J.P., 2011. Nearinfrared spectroscopy: a novel, noninvasive, diagnostic method for detrusor overac tivity in patients with overactive bladder symptoms-a preliminary and experimenta study. Eur. Urol 59, 757-762. http://dx.doi.org/10.1016/j.eururo.2010.12.032.

Fernbach, S.K., Feinstein, K.A., Schmidt, M.B., 2000. Pediatric voiding cystourethrography: a pictorial guide. Radiographics 20,155-168. http://dx.doi.org/10.1148/radiographics.20. 1.g00ja12155 discussion 168-71.

Fukuyama, H., Matsuzaki, S., Ouchi, Y., Yamauchi, H., Nagahama, Y., Kimura, J., Shibasaki, H., 1996. Neural control of micturition in man examined with single photon emission computed tomography using 99mTc-HMPAO. Neuroreport 7, 3009-3012.

Griffiths, D.J., 2002. The pontine micturition centres. Scand. J. Urol. Nephrol. Suppl 21-26.

Griffiths, D.J., Fowler, C.J., 2013. The micturition switch and its forebrain influences. Acta Physiol (Oxford) 207, 93-109. http://dx.doi.org/10.1111/apha.12019.

Griffiths, D., Tadic, S.D., 2008. Bladder control, urgency, and urge incontinence: evidence from functional brain imaging. Neurourol. Urodyn 27, 466-474. http://dx.doi.org/ 10.1002/nau.20549.

Griffiths, D., Derbyshire, S., Stenger, A., Resnick, N., 2005. Brain control of normal and overactive bladder. J. Urol 174, 1862-1867. http://dx.doi.org/10.1097/01.ju. 0000177450.34451 .97$.

Griffiths, D., Tadic, S.D., Schaefer, W., Resnick, N.M., 2007. Cerebral control of the bladder in normal and urge-incontinent women. Neurolmage 37, 1-7. http://dx.doi.org/10. 1016/j.neuroimage.2007.04.061.

Griffiths, D.J., Tadic, S.D., Schaefer, W., Resnick, N.M., 2009. Cerebral control of the lowe urinary tract: how age-related changes might predispose to urge incontinence. NeuroImage 47, 981-986. http://dx.doi.org/10.1016/j.neuroimage.2009.04.087.

Hakim, L., Endo, M., Feola, A., Soebadi, D.M., Deprest, J., De Ridder, D., Albersen, M., Van Der Aa, F., 2014. High-frequency micro-ultrasound: a novel method to assess external urethral sphincter function in rats following simulated birth injury. Neurourol Urodyn http://dx.doi.org/10.1002/nau.22555.

Herzog, J., Weiss, P.H., Assmus, A., Wefer, B., Seif, C., Braun, P.M., Herzog, H., Volkmann, J. Deuschl, G., Fink, G.R., 2006. Subthalamic stimulation modulates cortical control of urinary bladder in Parkinson's disease. Brain 129, 3366-3375. http://dx.doi.org/10. 1093/brain/awl302.

Herzog, J., Weiss, P.H., Assmus, A., Wefer, B., Seif, C., Braun, P.M., Pinsker, M.O., Herzog, H., Volkmann, J., Deuschl, G., Fink, G.R., 2008. Improved sensory gating of urinary bladder afferents in Parkinson's disease following subthalamic stimulation. Brain 131, 132-145. http://dx.doi.org/10.1093/brain/awm254.

Idzenga, T., Farag, F., Heesakkers, J., Feitz, W., de Korte, C.L., 2013. Noninvasive 2dimensional monitoring of strain in the detrusor muscle in patients with lower urinary tract symptoms using ultrasound strain imaging. J. Urol 189, 1402-1408. http://dx.doi.org/10.1016/j.juro.2012.09.165. 
Ikeda, R., Suga, K., Suzuki, K., 2001. MRI appearance of a leiomyoma of the female urethra. Clin. Radiol 56, 76-79.

Kanai, A., Andersson, K.-E., 2010. Bladder afferent signaling: recent findings. J. Urol 183, 1288-1295. http://dx.doi.org/10.1016/j.juro.2009.12.060.

Kavia, R., Dasgupta, R., Critchley, H., Fowler, C., Griffiths, D., 2010. A functional magnetic resonance imaging study of the effect of sacral neuromodulation on brain response in women with Fowler's syndrome. 105, 366-372. http://dx.doi.org/10.1111/j.1464410X.2009.08819.X

Kershaw, L.E., Hutchinson, C.E., Buckley, D.L., 2009. Benign prostatic hyperplasia: evaluation of $\mathrm{T} 1, \mathrm{~T} 2$, and microvascular characteristics with T1-weighted dynamic contrast-enhanced MRI. J. Magn. Reson. Imaging 29, 641-648. http://dx.doi.org/10.1002/jmri.21674.

Kessler, T.M., Gerber, R., Burkhard, F.C., Studer, U.E., Danuser, H., 2006. Ultrasound assessment of detrusor thickness in men-can it predict bladder outlet obstruction and replace pressure flow study? J. Urol 175, 2170-2173. http://dx.doi.org/10.1016/ S0022-5347(06)00316-8.

Kim, J.K., Kim, Y.J., Choo, M.S., Cho, K.-S., 2003. The urethra and its supporting structures in women with stress urinary incontinence: MR imaging using an endovaginal coil AJ. Am. J. Roentgenol 180, 1037-1044. http://dx.doi.org/10.2214/ajr.180.4.1801037.

Kim, B., Kawashima, A., LeRoy, A.J., 2007. Imaging of the male urethra. Semin. Ultrasound CT MR 28, 258-273.

Kirschner-Hermanns, R., Wein, B., Niehaus, S., Schaefer, W., Jakse, G., 1993. The contribution of magnetic resonance imaging of the pelvic floor to the understanding of urinary incontinence. Br. J. Urol 72, 715-718.

Kitta, T., Kakizaki, H., Furuno, T., Moriya, K., Tanaka, H., Shiga, T., Tamaki, N., Yabe, I., Sasaki, H., Nonomura, K., 2006. Brain activation during detrusor overactivity in patients with Parkinson's disease: a positron emission tomography study. J. Urol 175 994-998. http://dx.doi.org/10.1016/S0022-5347(05)00324-1.

Kojima, M., Inui, E., Ochiai, A., Naya, Y., Ukimura, O., Watanabe, H., 1997. Noninvasive quantitative estimation of infravesical obstruction using ultrasonic measurement of bladder weight. J. Urol 157, 476-479.

Komesu, Y.M., Ketai, L.H., Mayer, A.R., Teshiba, T.M., Rogers, R.G., 2011. Functional MRI of the brain in women with overactive bladder: Brain activation during urinary urgency. Female Pelvic Med. Reconstr. Surg 17, 50-54. http://dx.doi.org/10.1097/SPV. 0b013e3182065507.

Kranse, R., van Mastrigt, R., 2003. Weak correlation between bladder outlet obstruction and probability to void to completion. Urology 62, 667-671.

Krhut, J., Holy, P., Tintera, J., Zachoval, R., Zvara, P., 2013. Brain activity during bladder filling and pelvic floor muscle contractions: A study using functional magnetic resonance imaging and synchronous urodynamics. Int. J. Urol 21, 169-174. http://dx. doi.org/10.1111/iju.12211.

Ku, J.H., Ko, D.W., Cho, J.Y., Oh, S.-J., 2010. Correlation between prostatic urethral angle and bladder outlet obstruction index in patients with lower urinary tract symptoms. Urology 75, 1467-1471. http://dx.doi.org/10.1016/j.urology.2009.08.049.

Kuhtz-Buschbeck, J.P., van der Horst, C., Pott, C., Wolff, S., Nabavi, A., Jansen, O., Junemann, K.P., 2005. Cortical representation of the urge to void: a functional magnetic resonance imaging study. J. Urol 174, 1477-1481.

Kuhtz-Buschbeck, J.P., van der Horst, C., Wolff, S., Filippow, N., Nabavi, A., Jansen, O., Braun, P.M., 2007. Activation of the supplementary motor area (SMA) during voluntary pelvic floor muscle contractions-an fMRI study. NeuroImage 35 449-457. http://dx.doi.org/10.1016/j.neuroimage.2006.12.032.

Kuhtz-Buschbeck, J.P., Gilster, R., van der Horst, C., Hamann, M., Wolff, S., Jansen, O., 2009. Control of bladder sensations: an fMRI study of brain activity and effective connectivity. NeuroImage 47, 18-27. http://dx.doi.org/10.1016/j.neuroimage.2009.04.020

Kuipers, R., Mouton, L.J., Holstege, G., 2006. Afferent projections to the pontine micturition center in the cat. J. Comp. Neurol 494, 36-53. http://dx.doi.org/10.1002/cne.20775.

Lim, K.B., Ho, H., Foo, K.T., Wong, M.Y.C., Fook-Chong, S., 2006. Comparison of intravesical prostatic protrusion, prostate volume and serum prostatic-specific antigen in the evaluation of bladder outlet obstruction. Int. J. Urol 13, 1509-1513. http://dx.doi. org/10.1111/j.1442-2042.2006.01611.x.

Loewy, A.D., Saper, C.B., Baker, R.P., 1979. Descending projections from the pontine micturition center. Brain Res 172, 533-538.

Lone, F., Sultan, A.H., Stankiewicz, A., Thakar, R., Wieczorek, A.P., 2014. Vascularity of the urethra in continent women using colour doppler high-frequency endovaginal ultrasonography. Springerplus 3, 619 .

Macnab, A.J., Stothers, L., 2008. Near-infrared spectroscopy: validation of bladder-outle obstruction assessment using non-invasive parameters. Can. J. Urol 15, 4241-4248.

Macnab, A.J., Shadgan, B., Stothers, L., Afshar, K., 2013. Ambulant monitoring of bladder oxygenation and hemodynamics using wireless near-infrared spectroscopy. Can. Urol. Assoc. J 7, E98-E104

Macura, K.J., Genadry, R.R., Bluemke, D.A., 2006. MR imaging of the female urethra and supporting ligaments in assessment of urinary incontinence: spectrum of abnormalities. Radiographics 26, 1135-1149. http://dx.doi.org/10.1148/rg.264055133.

Maglinte, D.D.T., Bartram, C.I., Hale, D.A., Park, J., Kohli, M.D., Robb, B.W., Romano, S. Lappas, J.C., 2011. Functional imaging of the pelvic floor. Radiology 258, 23-39. http://dx.doi.org/10.1148/radiol.10092367.

Manieri, C., Carter, S.S., Romano, G., Trucchi, A., Valenti, M., Tubaro, A., 1998. The diagnosis of bladder outlet obstruction in men by ultrasound measurement of bladder wall thickness. J. Urol 159, 761-765.

Mantyh, P.W., 1983. Connections of midbrain periaqueductal gray in the monkey. I. Ascending efferent projections. 49, 567-581.

Mariappan, P., Brown, D.J.G., McNeill, A.S., 2007. Intravesical prostatic protrusion is better than prostate volume in predicting the outcome of trial without catheter in white men presenting with acute urinary retention: a prospective clinical study. J. Urol 178, 573-577. http://dx.doi.org/10.1016/j.juro.2007.03.116 discussion 577.

Marks, B.K., Goldman, H.B., 2014. Videourodynamics: indications and technique. Urol. Clin. N. Am 41, 383-391. http://dx.doi.org/10.1016/j.ucl.2014.04.008 vii-viii.
Mastoroudes, H., Giarenis, I., Vella, M., Srikrishna, S., Robinson, D., Cardozo, L., Karrouze, I., Campbell, A., Macnab, A., 2012. Use of near infrared spectroscopy as an alternative to videourodynamics to detect detrusor overactivity in women with the overactive bladder syndrome. Urology 80, 547-550. http://dx.doi.org/10.1016/j.urology.2012. 05.036

Matsumoto, S., Ishikawa, A., Kume, H., Takeuchi, T., Homma, Y., 2009. Near infrared spectroscopy study of the central nervous activity during artificial changes in bladder sensation in men. Int. J. Urol 16, 760-764. http://dx.doi.org/10.1111/j.1442-2042. 2009.02358.x.

Matsumoto, S., Ishikawa, A., Matsumoto, S., Homma, Y., 2011. Brain response provoked by different bladder volumes: a near infrared spectroscopy study. Neurourol. Urodyn 30, 529-535. http://dx.doi.org/10.1002/nau.21016.

Matsuura, S., Kakizaki, H., Mitsui, T., Shiga, T., Tamaki, N., Koyanagi, T., 2002. Human brain region response to distention or cold stimulation of the bladder: a positron emission tomography study. J. Urol 168, 2035-2039. http://dx.doi.org/10.1016/S00225347(05)64290-5.

Mehnert, U., Boy, S., Svensson, J., Michels, L., Reitz, A., Candia, V., Kleiser, R., Kollias, S., Schurch, B., 2008. Brain activation in response to bladder filling and simultaneous stimulation of the dorsal clitoral nerve-an fMRI study in healthy women. NeuroImage 41, 682-689. http://dx.doi.org/10.1016/j.neuroimage.2008.03.006.

Mehnert, U., Michels, L., Zempleni, M.-Z., Schurch, B., Kollias, S., 2011. The supraspinal neural correlate of bladder cold sensation-an fMRI study. Hum. Brain Mapp. 32, 835-845. http://dx.doi.org/10.1002/hbm.21070.

Mier, W., Mier, D., 2015. Advantages in functional imaging of the brain. Front. Hum. Neurosci 9, 249. http://dx.doi.org/10.3389/fnhum.2015.00249.

Nardos, R., Gregory, W.T., Krisky, C., Newell, A., Nardos, B., Schlaggar, B., Fair, D.A., 2013. Examining mechanisms of brain control of bladder function with resting state functional connectivity MRI. Neurourol. Urodyn 33, 493-501. http://dx.doi.org/10.1002/nau.22458.

Nathan, P.W., Andrew, J., 1964. Lesions of the anterior frontal lobes and disturbances of micturition and defaecation. Brain 87, 233-262.

Nour, S., Svarer, C., Kristensen, J., Paulson, O.B., Law, I., 2000. Cerebral activation during micturition in normal men. Brain 123, 781-789. http://dx.doi.org/10.1093/brain/ 123.4.781.

Oelke, M., Hofner, K., Jonas, U., Ubbink, D., de la Rosette, J., Wijkstra, H., 2006. Ultrasound measurement of detrusor wall thickness in healthy adults. Neurourol. Urodyn 25, 308-317. http://dx.doi.org/10.1002/nau.20242 discussion 318.

Oelke, M., Hofner, K., Jonas, U., de la Rosette, J.J., Ubbink, D.T., Wijkstra, H., 2007. Diagnostic accuracy of noninvasive tests to evaluate bladder outlet obstruction in men: detrusor wall thickness, uroflowmetry, postvoid residual urine, and prostate volume. Eur. Urol 52, 827-834. http://dx.doi.org/10.1016/j.eururo.2006.12.023.

Park, Y.J., Bae, K.H., Jin, B.S., Jung, H.J., Park, J.S., 2012. Is increased prostatic urethral angle related to lower urinary tract symptoms in males with benign prostatic hyperplasia/ lower urinary tract symptoms? Korean J. Urol 53, 410-413. http://dx.doi.org/10. 4111/kju.2012.53.6.410.

Parsons, B.A., Bright, E., Shaban, A.M., Whitehouse, A., Drake, M.J., 2011. The role of invasive and non-invasive urodynamics in male voiding lower urinary tract symptoms. World J. Urol 29, 191-197. http://dx.doi.org/10.1007/s00345-009-0488-8.

Prasad, S.R., Menias, C.O., Narra, V.R., Middleton, W.D., Mukundan, G., Samadi, N., Heiken, J.P., Siegel, C.L., 2005. Cross-sectional imaging of the female urethra: technique and results. Radiographics 25, 749-761. http://dx.doi.org/10.1148/rg.253045067.

Ren, J., Huan, Y., Wang, H., Zhao, H., Ge, Y., Chang, Y., Liu, Y., 2008. Diffusion-weighted imaging in normal prostate and differential diagnosis of prostate diseases. Abdom. Imaging 33, 724-728. http://dx.doi.org/10.1007/s00261-008-9361-2.

Romanzi, L.J., Groutz, A., Blaivas, J.G., 2000. Urethral diverticulum in women: diverse presentations resulting in diagnostic delay and mismanagement. J. Urol 164, 428-433.

Sakakibara, R., Tsunoyama, K., Takahashi, O., Sugiyama, M., Kishi, M., Ogawa, E., Uchiyama, T., Yamamoto, T., Yamanishi, T., Awa, Y., Yamaguchi, C., 2010. Real-time measurement of oxyhemoglobin concentration changes in the frontal micturition area: an fNIRS study. Neurourol. Urodyn 29, 757-764. http://dx.doi.org/10.1002/nau.20815.

Sakakibara, R., Tateno, F., Yano, M., Takahashi, O., Sugiyama, M., Ogata, T., Haruta, H., Kishi, M., Tsuyusaki, Y., Yamamoto, T., Uchiyama, T., Yamanishi, T., Yamaguchi, C., 2013. Imidafenacin on bladder and cognitive function in neurologic OAB patients. Clin. Auton. Res 23, 189-195. http://dx.doi.org/10.1007/s10286-013-0200-3.

Sakakibara, Tateno, F., Yano, M., Takahashi, O., Sugiyama, M., Ogata, T., Kishi, M., Tsuyusaki, Y., Yamamoto, T., Uchiyama, T., Yamanishi, T., Shibata, C., 2014. Tolterodine activates the prefrontal cortex during bladder filling in OAB patients: a real-time NIRS-urodynamics study. Neurourol. Urodyn 33, 1110-1115. http://dx. doi.org/10.1002/nau.22471.

Salah Azab, S., Elsheikh, M.G., 2014. The impact of the bladder wall thickness on the outcome of the medical treatment using alpha-blocker of BPH patients with LUTS. Aging Male 1-4 http://dx.doi.org/10.3109/13685538.2014.967672.

Santoro, G.A., Wieczorek, A.P., Stankiewicz, A., Wozniak, M.M., Bogusiewicz, M., Rechberger, T., 2009. High-resolution three-dimensional endovaginal ultrasonography in the assessment of pelvic floor anatomy: a preliminary study. Int. Urogynecol. J. Pelvic Floor Dysfunct 20, 1213-1222. http://dx doi.org/10.1007/s00192-009-0928-4.

Seseke, S., Baudewig, J., Kallenberg, K., Ringert, R.-H., Seseke, F., Dechent, P., 2006. Voluntary pelvic floor muscle control-an fMRI study. NeuroImage 31, 1399-1407. http://dx.doi.org/10.1016/j.neuroimage.2006.02.012.

Seseke, S., Baudewig, J., Kallenberg, K., Ringert, R.-H., Seseke, F., Dechent, P., 2008. Gender differences in voluntary micturition control: an fMRI study. NeuroImage 43, 183-191. http://dx.doi.org/10.1016/j.neuroimage.2008.07.044.

Shinbo, H., Kurita, Y., 2011. Application of ultrasonography and the resistive index for evaluating bladder outlet obstruction in patients with benign prostatic hyperplasia. Curr. Urol. Rep 12, 255-260. http://dx.doi.org/10.1007/s11934-011-0189-X.

Shinbo, H., Kurita, Y., Takada, S., Imanishi, T., Otsuka, A., Furuse, H., Nakanishi, T., Mugiya, S., Ozono, S., 2010. Resistive index as risk factor for acute urinary retention in patients 
with benign prostatic hyperplasia. Urology 76, 1440-1445. http://dx.doi.org/10.1016/ j.urology.2010.04.026.

Shy, M., Fung, S., Boone, T.B., Karmonik, C., Fletcher, S.G., Khavari, R., 2014. Functional magnetic resonance imaging during urodynamic testing identifies brain structures initiating micturition. J. Urol http://dx.doi.org/10.1016/j.juro.2014.04.090.

St Sauver, J.L., Jacobson, D.J., McGree, M.E., Girman, C.J., Nehra, A., Lieber, M.M., Jacobsen, S.J., 2009. Presumed circle area ratio of the prostate in a community-based group of men. BJ. Int. 104, 58-62. http://dx.doi.org/10.1111/j.1464-410X.2009.08354.x.

Steensma, A.B., Oom, D.M.J., Burger, C.W., Schouten, W.R., 2010. Assessment of posterior compartment prolapse: a comparison of evacuation proctography and 3D transperineal ultrasound. Color. Dis 12, 533-539. http://dx.doi.org/10.1111/j.14631318.2009.01936.

Surabhi, V.R., Menias, C.O., George, V., Siegel, C.L., Prasad, S.R., 2013. Magnetic resonance imaging of female urethral and periurethral disorders. Radiol. Clin. N. Am 51, 941-953. http://dx.doi.org/10.1016/j.rcl.2013.07.001.

Tadic, S.D., Griffiths, D., Schaefer, W., Resnick, N.M., 2008. Abnormal connections in the supraspinal bladder control network in women with urge urinary incontinence. Neurolmage 39, 1647-1653. http://dx.doi.org/10.1016/j.neuroimage.2007.10.059.

Tadic, S.D., Griffiths, D., Murrin, A., Schaefer, W., Aizenstein, H.J., Resnick, N.M., 2010a. Brain activity during bladder filling is related to white matter structural changes in older women with urinary incontinence. Neurolmage 51, 1294-1302. http://dx.doi. org/10.1016/j.neuroimage.2010.03.016.

Tadic, S.D., Griffiths, D., Schaefer, W., Cheng, C.I., Resnick, N.M., 2010b. Brain activity measured by functional magnetic resonance imaging is related to patient reported urgency urinary incontinence severity. J. Urol 183, 221-228. http://dx.doi.org/10. 1016/j.juro.2009.08.155.

Tadic, S.D., Griffiths, D., Schaefer, W., Murrin, A., Clarkson, B., Resnick, N.M., 2012. Brain activity underlying impaired continence control in older women with overactive bladder. Neururol. Urodyn. 31, 652-658. http://dx.doi.org/10.1002/nau.21240.

Tadic, S.D., Tannenbaum, C., Resnick, N.M., Griffiths, D., 2013. Brain responses to bladder filling in older women without urgency incontinence. Neurourol. Urodyn 32, 435-440. http://dx.doi.org/10.1002/nau.22320.

Tai, C., Wang, J., Jin, T., Wang, P., Kim, S.-G., Roppolo, J.R., de Groat, W.C., 2009. Brain switch for reflex micturition control detected by FMRI in rats. J. Neurophysiol 102, 2719-2730. http://dx.doi.org/10.1152/jn.00700.2009.

Tubaro, A., Carter, S., Hind, A., Vicentini, C., Miano, L., 2001. A prospective study of the safety and efficacy of suprapubic transvesical prostatectomy in patients with benign prostatic hyperplasia. J. Urol 166, 172-176.
Vertes, R.P., 2001. Analysis of projections from the medial prefrontal cortex to the thalamus in the rat, with emphasis on nucleus reuniens. J. Comp. Neurol 442, 163-187. http://dx.doi.org/10.1002/cne.10083.

Wieczorek, A.P., Stankiewicz, A., Santoro, G.A., Wozniak, M.M., Bogusiewicz, M. Rechberger, T., 2011. Pelvic floor disorders: role of new ultrasonographic techniques. World J. Urol 29, 615-623. http://dx.doi.org/10.1007/s00345-011-0708-x.

Winge, K., Fowler, C.J., 2006. Bladder dysfunction in Parkinsonism: mechanisms, prevalence, symptoms, and management. Mov. Disord 21, 737-745. http://dx.doi.org/10. 1002/mds.20867.

Wong, K., Boone, T.B., Wong, S.T.C., Munoz, A., 2014. Functional brain interactions during reflexive micturition are absent from spinal cord injured rats with neurogenic bladder. Neurourol. Urodyn http://dx.doi.org/10.1002/nau.22596.

Wood, J.N., Grafman, J., 2003. Human prefrontal cortex: processing and representational perspectives. Nat. Rev. Neurosci 4, 139-147. http://dx.doi.org/10.1038/nrn1033.

Yamamoto, T., Sakakibara, R., Nakazawa, K., Uchiyama, T., Shimizu, E., Hattori, T., 2009. Effects of electrical stimulation of the striatum on bladder activity in cats. Neurourol. Urodyn 28, 549-554. http://dx.doi.org/10.1002/nau.20682.

Yin, Y., Shuke, N., Okizaki, A., Sato, J., Aburano, T., Li, Y., Kaneko, S., Mizunaga, M., Yachiku, S., 2006. Cerebral activation during withholding urine with full bladder in healthy men using 99mTc-HMPAO SPECT. J. Nucl. Med. 47, 1093-1098.

Yingling, C.D., Skinner, J.E., 1976. Selective regulation of thalamic sensory relay nuclei by nucleus reticularis thalami. Electroencephalogr. Clin. Neurophysiol 41, 476-482.

Yuen, J.S.P., Ngiap, J.T.K., Cheng, C.W.S., Foo, K.T., 2002. Effects of bladder volume on transabdominal ultrasound measurements of intravesical prostatic protrusion and volume. Int. J. Urol 9, 225-229.

Yurt, M., Suer, E., Gulpinar, O., Telli, O., Arikan, N., 2012. Diagnosis of bladder outlet obstruction in men with lower urinary tract symptoms: comparison of near infrared spectroscopy algorithm and pressure flow study in a prospective study. Urology 80 182-186. http://dx.doi.org/10.1016/j.urology.2012.03.022.

Zhang, H., Reitz, A., Kollias, S., Summers, P., Curt, A., Schurch, B., 2005. An fMRI study of the role of suprapontine brain structures in the voluntary voiding control induced by pelvic floor contraction. Neurolmage 24, 174-180. http://dx.doi.org/10.1016/j. neuroimage.2004.08.027.

Zempleni, M.-Z., Michels, L., Mehnert, U., Schurch, B., Kollias, S., 2010. Cortical substrate of bladder control in $\mathrm{SCl}$ and the effect of peripheral pudendal stimulation. Neurolmage 49, 2983-2994. http://dx.doi.org/10.1016/j.neuroimage.2009.10.064. 